\title{
Experimental Study and Numerical Simulation of Plane Steel Frame with Rubberized Connecting Technology Subjected to Seismic Effect
}

\author{
Suhaib J. Ali ${ }^{\text {a* }}$, Amer M. Ibrahim (D) b, Sarmad Shafeeq (iD c \\ a Department Of Civil Engineering University Of Technology, Baghdad, Iraq.suhaib55@yahoo.com \\ ${ }^{\mathrm{b}}$ Department Of Civil Engineering University Of Diyala, Diyala, Iraq.amereng76@yahoo.com \\ ${ }^{\mathrm{c}}$ Department Of Civil Engineering University Of Technology, Baghdad, Iraq, \\ 40010@uotechnology.edu.iq
}

*Corresponding author.

Submitted: 16/12/2019

Accepted: 04/02/2020

Published: 25/03/2021

K E Y W O R D S

Steel Frame, Seismic,

Rubber, Cyclic, FEM.

\section{A B S T R A C T}

\begin{abstract}
This paper represents experimental and numerical study of the behavior of the rubberized steel frame connections. One single-bay, one-story without elastic buckling are cyclically tested. The experimental specimens are simulated and analyzed by the ABAQUS program. Four specimens of steel plane portal frame are investigated under horizontal reversed cyclic loads. The specimen connections are developed by using different diameters of composite steel bolts/rubber instead of conventional steel bolts to connect the beams with columns. The yield and ultimate strength, ductility, envelope curves, and damping ratio of these specimens are analyzed and compared. The finite element method is used to establish and verify the results of the laboratory test. The results of the experimental and numerical tests gave a large load-carrying capacity, reduction in the stresses, excellent ductility and energy dissipation capacity, and remarkably improved damping ratio.
\end{abstract}

How to cite this article: S. J. Ali, A. M. Ibrahim, and S. Shafeeq, "Experimental Study and Numerical Simulation of Plane Steel Frame with Rubberized Connecting Technology Subjected to Seismic Effect," Engineering and Technology Journal, Vol. 39, Part A, No. 03, pp. 415-425, 2021.

DOI: https://doi.org/10.30684/etj.v39i3A.1500

This is an open access article under the CC BY 4.0 license http://creativecommons.org/licenses/by/4.0

\section{INTRODUCTION}

Earthquakes are a geophysical phenomenon that appears a wave rises and falls to the ground. These waves move to the foundations of the buildings and move it and the body of the buildings will respond due to these waves and moves contrary to the foundation movements and failure occurs. Iraq is in a seismic zone; therefore, it is becoming necessary to study how to reduce the effect of seismic effect on buildings. There are many methods to reduce the effect of seismic loads on buildings such 
as shear wall system, isolation system, and damper system. This study scoped to develop the beamto-column connections in the steel buildings according to the principle of the isolation system. Failure of joints is the most common type of failure and the most repeated in steel structures where it is possible to design steel members very accurately, while for the design of steel joints becomes more complex, calculations through looking at the maximum load and then design the joint for the maximum possible strength. In general, the joints fail first in the event of an unexpected force because it is logical that any steel member can be resisted by secondary loads because the steel section is poured in one part, while the joints behaves as a brittle material where it takes some loads but not all, therefore, the idea of studying and developing the joints of steel building through the innovative of rubberized connecting technology capable to absorb and dissipate these loads was the main objectives of this research. The beams relate to columns by composites steel bolts/rubber, these bolts made by covering the traditional steel bolts by different rubber thickness, where these rubbers taken from waste tires. There are several studies within the field of earthquakes and shear tap connections such as: [1], this study presented the effect of seismic loads by applied the cyclic loads in the top ends of steel frames with shear tabs connections. This study found new approach to resist the seismic effect through creating gaps between steel frame and shear wall. [2], the behavior of the full-scale test of common shear tabs connection under combined load investigated by this study. Failure mode, ductility limits, and connection capacities were presented and discussed, the results were described to find an applied approach to finding the performance for beam-column connection under column removal scenarios. The failure of bolts-tear out was the governing failure under the combined load at shear tab connections. Shear connection with additional seat caused a significant low rotation and rise in the moments as well as improvement of overall capacity at the ultimate limit state. [3], the numerical study to determine the moment-rotation relationship of the shear tab connections type, by using the ABAQUS programis determined by this paper. This study assumed that the idealization of supposing that shear tabs will not resist the moment is incorrect while computing the lateral stiffness of a steel frame. Schroeder calculated the initial stiffness of the connections in a footnote of (2-12\%), and the results proved that if the connection was partially restrained connections, the inter-story drift of structure might be decreased by (22\%) compared to a situation of shear tabs that are supposed to be perfect pin connections.

\section{Experimental Program}

Four plane steel frames are designed and formed according to AISC $-14^{\text {Th }}$ edition [4] consisted of two vertical steel columns sections HW125 $\times 125$ with length $1500 \mathrm{~mm}$ and one of horizontal beam section IEP160 with length $1000 \mathrm{~mm}$. The columns connected with beams by using a single shear tab connection with dimensions $110 \times 90 \times 8 \mathrm{~mm}$ welded in the columns from one hand and bolted with the web of the beams on the other hand. One of the columns represented a fixed column andthe other pinned. Two bolts are uses in each joint of the steel frame to connect the shear tabs with beams. The FR1 was reference frame for the specimens. The columns bolted with the beam by steel bolts only for the reference frame, while the other steel frames FR2, FR3, and FR4 the columns connected with beams by different diameters of composites steel bolts/rubber. Holes of shear tab connections driven to suitable with the diameter of the composites steel bolts/rubber such as standard holes, short-slotted holes, oversize holes, and long-slotted holes. 


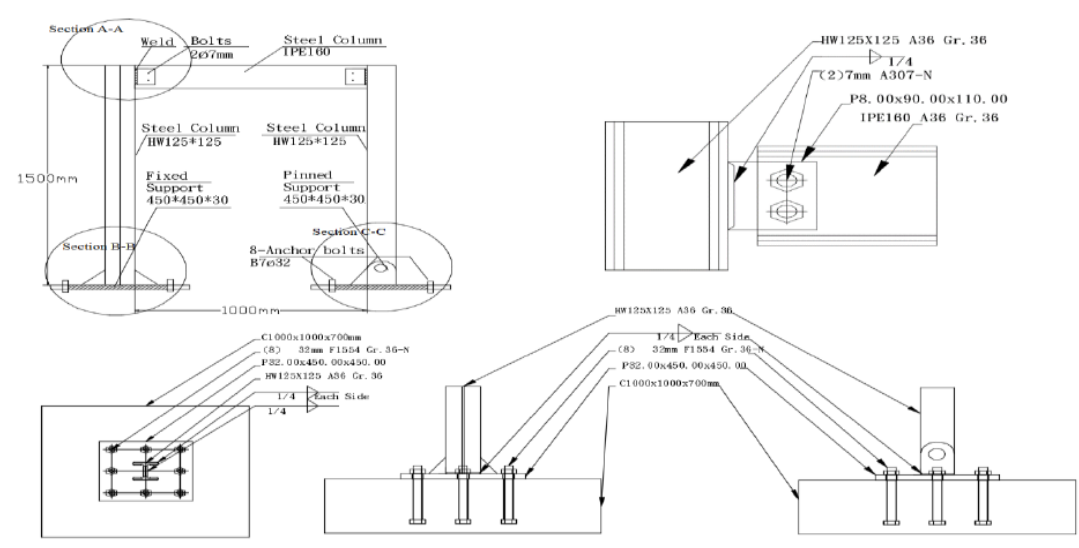

Figure 1: Details of tested specimens.

\section{Material}

This study includes the following materials:

- Mild carbon steel columns HW125 $\times 125$ conforming to the Chinese specification, the mechanical proprieties for these sections found according to the standard test method [5] on laboratories of Diyala company-engineering industries as shown Table I.

- Mild carbon steel beam IPE160 conforms to European specifications, the mechanical properties for the beams sections established by tensile testing according to the standard test method [5] as shown in Table I.

- Single shear tab connections welded in columns and bolted with beams. The yield and ultimate loads for these plates are listed in Table I.

- Two of the steel bolts used to connect the shear plate with the beam web on each side of the specimen connections. Size of these bolts A307-N 7mm $\times 35 \mathrm{~mm}$. Two washers are used for each bolt; one washer position between the head bolts and shear plate, the other one attaches with the bolt nut and beam web. Usually, the washers are used on the connections to prevent the damage on the face of the connection as well as to distribute the load under the bolt head and nut. The mechanical properties of the tensile strength for these steel bolts used are found according to Standard Specification for Carbon Steel Bolts and Studs [6] as Table II.

TABLE I: Mechanical properties of steel sections

\begin{tabular}{ccccc}
\hline \hline Member & $\begin{array}{c}\text { Yield Strength } \\
\text { (MPa }\end{array}$ & $\begin{array}{c}\text { Ultimate Strength } \\
(\mathbf{M P a})\end{array}$ & $\begin{array}{c}\text { Elongation } \\
(\mathbf{\%})\end{array}$ & $\begin{array}{c}\text { Elastic Modulus } \\
(\mathbf{M P a})\end{array}$ \\
\hline Column & 250 & 400 & 35 & $1.95 \times 10^{5}$ \\
\hline $\begin{array}{c}\text { Beam } \\
\text { plate }\end{array}$ & 250 & 400 & 32 & $1.87 \times 10^{5}$ \\
\cline { 2 - 5 } & 312 & 422 & 31 & $2.11 \times 10^{5}$ \\
\hline
\end{tabular}

TABLE II: Mechanical properties of the bolts

\begin{tabular}{|c|c|c|c|c|c|c|c|}
\hline \multirow{2}{*}{$\begin{array}{c}\text { Steel } \\
\text { Bolt } \\
\text { Grade }\end{array}$} & \multicolumn{5}{|c|}{ Tensile Test } & \multirow{2}{*}{$\begin{array}{c}\text { Shear } \\
\text { Test } \\
\text { Shear } \\
\text { Strenght } \\
\\
N /(\boldsymbol{m m})^{2}\end{array}$} & \multirow{2}{*}{$\begin{array}{l}\text { Elastic } \\
\text { Modulus } \\
(\mathrm{MPa}))\end{array}$} \\
\hline & $\begin{array}{c}\text { Yield } \\
\text { Strenght } \\
\text { N/ } \\
(\mathrm{mm})^{2} \\
\end{array}$ & $\begin{array}{c}\text { Tensile } \\
\text { Strenght } \\
\text { N/ } \\
(\mathrm{mm})^{2} \\
\end{array}$ & $\begin{array}{c}\text { ASTM } \\
\text { Standerd } \\
\text { Limatatio } \\
n \\
\end{array}$ & $\begin{array}{c}\text { Elongatio } \\
\boldsymbol{n} \\
(\%)\end{array}$ & $\begin{array}{c}\text { ASTM } \\
\text { Standard } \\
\text { Limitatio } \\
n \\
\end{array}$ & & \\
\hline $\begin{array}{c}\text { A307- } \\
\mathbf{N}\end{array}$ & 545 & 600 & $413 \mathrm{~min}$ & 33 & $18 \% \min$ & 302 & $2.75 \times 10^{5}$ \\
\hline
\end{tabular}

Finally, the rubber used to cover the steel bolts in different ratio of the bolt's dimeters $0.5 \boldsymbol{d}_{\text {bolt }}$, $1.0 \boldsymbol{d}_{\text {bolt }}$, and $1.5 \boldsymbol{d}_{\text {bolt }}$ by length $13 \mathrm{~mm}$, where the rubber is taken from old and used tires. The composites' steel bolts/rubber were made in the industrial district using a Turing machine. The 
process of cutting, manufacturing and fixing for these composites steel bolts was carried out in the factory as illustrated in Figure (2).

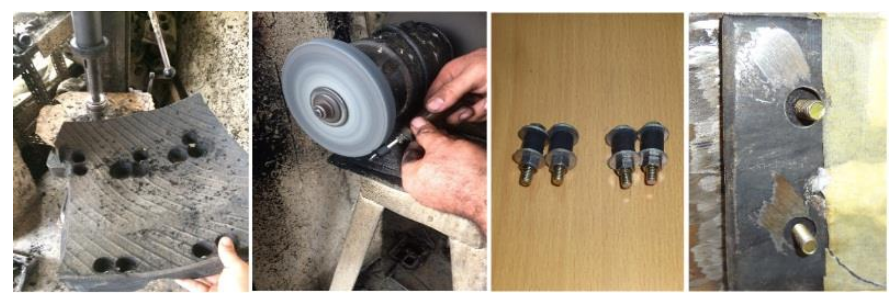

Figure 2: Process of the covered bolts by rubber

Properties of these rubber established on the Applied Sciences Laboratories-University of Technology. The tensile rubber test is from the Standard Test Method for Tensile Properties of Plastics 1 ( D638-14), by using the Jianqiao Testing Equipment, the tensile test is founded equally to 15.09 $\mathrm{MPa}$ and the elongation was equal to1204.1\%. Compression test for the rubber established according to American Society for Testing and Materials 2008 (D695 - 15), [8],the rate of alteration in sample length at each load points are taken to the extent of failure than the results of the compression test rubber are achieved as the Table III. Finally, The hardness test was performed by using Shore (A) Hardness Tester Th200 according to Standard Test Method for Rubber PropertyDurometer Hardness [9], where the rate of five readings are taken 84.7-89.9-82.7-84.7-86.3, the hardness of the rubber which is used in this study 85.66 Shore (A).

TABLE III: $\quad$ Compression Test Rubber

\begin{tabular}{ccccc}
\hline \hline \multirow{2}{*}{$\begin{array}{c}\text { Force } \\
(\mathrm{N})\end{array}$} & $\begin{array}{c}\text { Change on } \\
\text { Length } \\
\Delta \boldsymbol{L}(\mathbf{m m})\end{array}$ & $\begin{array}{c}\text { Compression } \\
\text { stress } \\
(\mathbf{M P a})\end{array}$ & $\begin{array}{c}\text { Strain } \\
\boldsymbol{\varepsilon}=\Delta \boldsymbol{L} / \boldsymbol{L}\end{array}$ & $\begin{array}{c}\text { Young's Modulus } \\
(\boldsymbol{M P a})\end{array}$ \\
\hline $\mathbf{0}$ & 0 & 0 & 0 & 0 \\
\hline $\mathbf{5 0 0}$ & 1.24 & 20 & 0.124 & 161.4 \\
\hline $\mathbf{7 0 0}$ & 3.94 & 28 & 0.396 & 70.7 \\
\hline $\mathbf{9 0 0}$ & 8.72 & 36 & 0.872 & 41.28 \\
\hline
\end{tabular}

\section{Test Setup}

The behavior of the four specimens' steel portal frames was investigated due to the seismic effect. Load-displacement hysteresis can be used to simulation seismic effect based on Structural Analysis and Design of Tall Buildings, ANSI/AISC 341-10,[10], through of applied the cyclic loads on the top ends of specimens, Figure (3) illustrated the machine loads and test approach for frames.

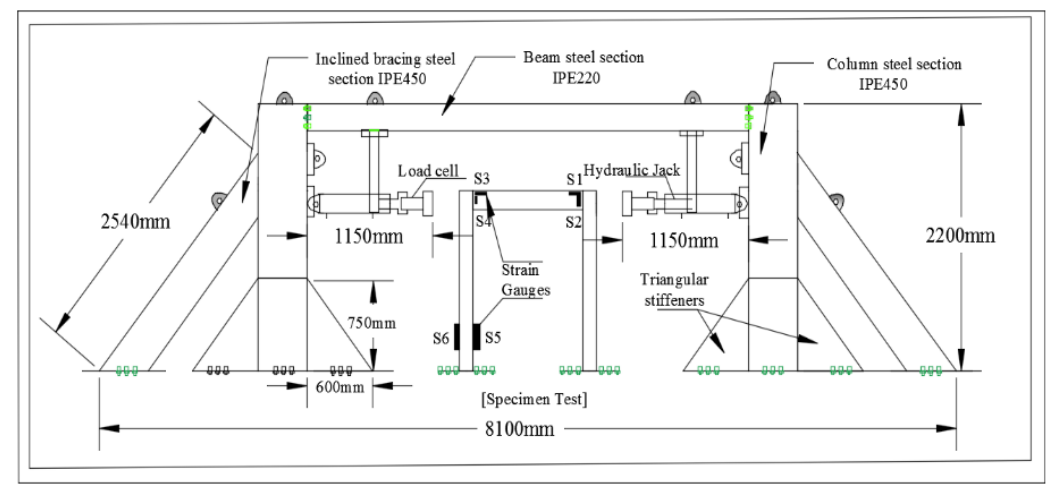

Figure 3: Test setup of specimens

Horizontal cyclic loads -quasi-static loads applied on the specimens according to the guidelines for cyclic seismic testing of components of steel structures [11]. Where this protocol is recommended by the U.S. for steel buildings test are investigated. ATC-24 was developed and used especially for 
steel structure components. The ATC-24 uses the elastic deformation concept for controlling the specimens' test. These protocol statements to apply six cycles before the yield point following three cycles at yield than three cycles of double yield loads as shown in Figure (4). These sequins and increases in the loading and number of cycles continue until the failure occurs. The same test program and loading protocol were applied to the specimen's test.

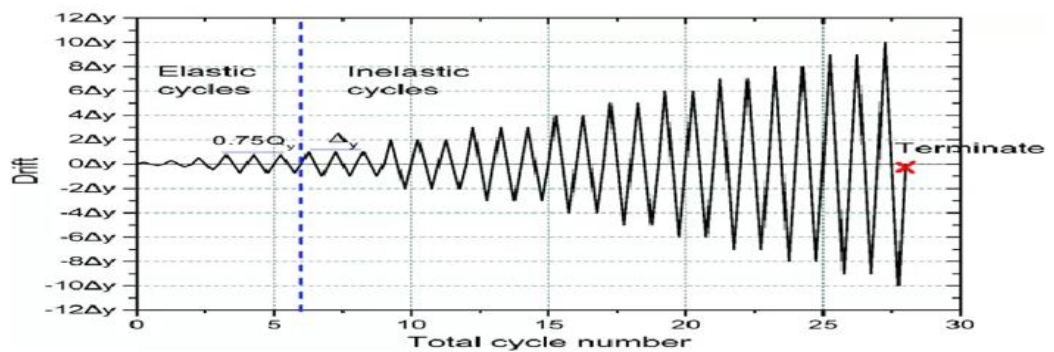

Figure 4: Deformation history for multiple-step test

The variables of the specimens for this study are listed in Table IV. All specimens are tested under horizontal reversed cyclic loads.

TABLE IV:Specimen Details

\begin{tabular}{cccccc}
\hline \hline $\begin{array}{c}\mathrm{N} \\
\mathbf{0}\end{array}$ & $\begin{array}{c}\text { Description } \\
\text { of } \\
\text { Specimens }\end{array}$ & Schedule & $\begin{array}{c}\text { Rubber ratio \% of } \\
\text { the Steel Bolt } \\
\text { diameter }\end{array}$ & $\begin{array}{c}\text { Holes } \\
\text { Type }\end{array}$ & Bolt diameter (mm) \\
\hline $\mathbf{1}$ & FR1 & Horizontal/Cyclic & 0 & Standard & $7.0 \mathrm{~mm}$ \\
\hline $\mathbf{2}$ & FR1 & Horizontal/Cyclic & 50 & Oversize & $10.5 \mathrm{~mm}$ \\
\hline $\mathbf{3}$ & FR3 & Horizontal/Cyclic & 100 & Short- Slotted & $14.0 \mathrm{~mm}$ \\
\hline $\mathbf{5}$ & FR4 & Horizontal/Cyclic & 150 & Long- Slotted & $17.5 \mathrm{~mm}$ \\
\hline
\end{tabular}

\section{Instrumentations}

Load of specimens are measurement by use two of load cells fixed at ends of hydraulic jacks as shown in Figure 3. The displacements of specimens found by using two of the Linear Variable Differential Transducer (LVDT) were fixed at the top of the frame used to measure the displacement during the cyclic load test. The strain of steel sections measures by using six steel strain gauge device and was glued in the stress positions as the mentions in Figure (3). All these external instrumentations were cabled with electronic devices recorded data over time (data logger).

\section{EXPERIMENTAL RESULTS}

\section{Predicate of P-A Values and Number of Cycles $\left(n_{c}\right)$ :}

The tests were done for the four specimens, the yield and ultimate loads investigated as well as the yield and ultimate displacements found for the specimens. The experimental test appeared in the specimens with rubber content on its joints to resist loads higher than without rubber. Where the rubberized specimens with ratio $50 \%, 100 \%$, and $150 \%$ of the steel bolts dimeters, the ultimate loads increased by $33 \%, 33 \%$, and $167 \%$ of the reference frame FR1. The rubberized steel connections enhanced the ability of the frames due to resisting displacement, where the displacement increased by $47 \%, 131 \%$, and $163 \%$. The results of the yield and ultimate loads and displacements are summarized in Table $\mathrm{V}$.

TABLE V: Results of Specimens under Horizontal Cyclic Loading Regime

\begin{tabular}{cccccc}
\hline \hline Specimens & $\begin{array}{c}\boldsymbol{P}_{\boldsymbol{y}} \\
\mathrm{kN}\end{array}$ & $\begin{array}{c}\boldsymbol{P}_{\boldsymbol{u}} \\
\mathrm{kN}\end{array}$ & $\begin{array}{c}\boldsymbol{\delta}_{\boldsymbol{y}} \\
\mathrm{mm}\end{array}$ & $\begin{array}{c}\boldsymbol{\delta}_{\boldsymbol{u}} \\
\mathrm{mm}\end{array}$ & $\boldsymbol{n}_{\boldsymbol{c}}$ \\
\hline FR1 & 20 & 30 & 11.92 & 17.85 & 10 \\
\hline FR2 & 30 & 40 & 21.70 & 26.24 & 16 \\
\hline FR3 & 40 & 40 & 26.24 & 41.18 & 16 \\
\hline FR4 & 40 & 80 & 26.99 & 47.00 & 40 \\
\hline
\end{tabular}


From Table V, notables that the maximum number of cycles for the reference frame FR1 was ten cycles only, while the frames with rubber ratio $50 \%$ and $100 \%$ resisted 16 cycles and the specimens which have rubber ratio $150 \%$ tolerance of 40 cycles. Using the rubber around the steel bolts prevented the contact between the shanks of steel bolts and holes of steel plates that leads to reduction in the pressure between the bolts and holes until the rubber reaches to the fatigue stage and the failure in the bolts are started in the steel joints. Increasing the diameter of composite steel bolts means that increased contact area leads to reduction in stress for the same load, therefore the yield and ultimate loads will be increased.

\section{Ductility}

All the ductility factors of the frames are reported in Table VI, the ductility index calculated based on the elastic displacement of the reference frame FR1. The results appeared that used the rubber by ratio $50 \%, 100 \%$, and $150 \%$ of the steel bolts diameter increased the ductility of frames by $2.125,3.375$, and 3.875 respectively, while the ductility of a reference frame which did not use the rubber on its joints was 1.375 . That means the rubber increased the ductility of specimens by 55\%, $145 \%$, and $182 \%$ of the reference frame. Use of the rubber in the steel joints dissipate the stresses and makes the steel frames work redistribution for these stresses so the steel frame component did not reach to the yield and ultimate loads for the same loads compared with the reference frame. On other hands, this smart connection delayed the yield and ultimate points for global frames and gave the capability of frames to withstand a larger offset displacement, where the calculation of the ductility index was according to equation $\mathrm{D}=\Delta_{u} / \Delta_{y}$, leads to an increase in the frames ductility.

TABLE VI: Ductility Index of Specimens under Horizontal Cyclic Loading

\begin{tabular}{ccccc}
\hline \hline $\begin{array}{c}\text { Designation } \\
\text { of }\end{array}$ & $\begin{array}{c}\text { Elastic Drift } \\
\left(\Delta_{\boldsymbol{y}}\right)\end{array}$ & $\begin{array}{c}\text { Ultimate Drift } \\
\left(\Delta_{\boldsymbol{u}}\right)\end{array}$ & $\begin{array}{c}\text { Ductility (D) } \\
\Delta_{\boldsymbol{u}} / \Delta_{\boldsymbol{y}}\end{array}$ & $\begin{array}{c}\text { Different } \\
\text { reference } \\
(\%)\end{array}$ \\
\hline Specimens & 0.008 & 0.011 & 1.375 & --- \\
\hline FR1 & 0.014 & 0.017 & 2.125 & 54.54 \\
\hline FR2 & 0.017 & 0.027 & 3.375 & 145.45 \\
\hline FR3 & 0.013 & 0.031 & 3.875 & 181.81 \\
\hline
\end{tabular}

\section{Damping Ratio}

Damping ratio is calculated based on half-power bandwidth method as to [12], where this method statement of the amplitude displacement to the steady-state frequency can be used for determining experimentally by the damping in a system at its natural frequencies. As the researcher appeared the results that are achieved by this method are very good for a single degree of freedom systems with small values of damping. The method statement can estimate the damping ratio $(\Sigma)$ from this expression:

$$
\Sigma=\frac{f_{b}-f_{a}}{2 \cdot f_{n}}
$$

Where:

$f_{n}=$ experimental natural frequency response at amplitude displacement $\left(A_{\max }\right)$.

$f_{a}=$ experimental natural frequency response at $\frac{A_{\max }}{\sqrt{2}}$ of amplitude displacement before $\left(f_{n}\right)$.

$f_{b}=$ experimental natural frequency response at $\frac{A_{\max }}{\sqrt{2}}$ of amplitude displacement $\operatorname{after}\left(f_{n}\right)$.

$A_{\max }=$ response amplitude displacement.

According to equation (1), the damping ratio calculated for the frames FR1, FR2, FR3, and FR4 were the results equaled to $0.0203,0.0208,0.0223$, and 0.0260 . The results illustrated the damping increased by increased thickness of the rubber, where the damping of specimens FR2, FR3, and FR4 improved by $2.46 \%, 15 \%$, and $28 \%$. Enhanced on the damping ratio can be explained based on the bandwidth concept, where the isolation system of the rubberized frames has bandwidth waves wider than the frame without a rubber. According to the damping ratio equation, there is a direct correlation 
between the damping ratio and bandwidth wave when increasing the bandwidth, the damping ratio will be increased.

\section{Finite Element AnAlysis \\ I. Finite element model}

Based on the experimental results of a plane steel frame, 3-D nonlinear finite element models were analyzed by using the general finite element program ABAQUS (2017) to establish the mechanical properties of these experimental specimens. The influences of both geometrical and material proprieties are taken into account. Selected the element shape was the first important geometry condition. Different types and order of the element were used in the FE models through the research until the results attached to the experimental test. First-order reduced integration C3D8R was selected for the all extended steel frame modeling.

\section{Material properties}

Hardening isotropic materials were used in the elastic zone for Young's modulus, Poisson ratio, and density. In the plastic zone hardening kinematic case are used to simulation the models. The finite element program required input data such as density, elastic modulus, and Poisson's ratio as illustrated in Table VII for the steel components of the frame. $7.83 \times 10^{\wedge}-9$

TABLE VII: $\quad$ Materials Proprieties for Components Frame

\begin{tabular}{lccccc}
\hline \hline No & $\begin{array}{c}\text { Material Model } \\
\text { Number }\end{array}$ & $\begin{array}{c}\text { Element } \\
\text { Type }\end{array}$ & & \multicolumn{3}{c}{ Material Properties } \\
\cline { 4 - 6 } & & & $\begin{array}{c}\text { Density, } \\
\boldsymbol{k g} \mathbf{m}^{\mathbf{3}}\end{array}$ & $\begin{array}{c}\text { Elastic Modulus, } \\
\boldsymbol{M P a}\end{array}$ & Poisson's Ratio, $\boldsymbol{v}$ \\
\hline $\mathbf{1}$ & Columns & Solid & 7830 & $1.95 \mathrm{e}+05$ & 0.3 \\
\hline $\mathbf{2}$ & Beam & Solid & 7830 & $1.87 \mathrm{e}+05$ & 0.3 \\
\hline $\mathbf{3}$ & Shear Plate & Solid & 7830 & $2.11 \mathrm{e}+05$ & 0.3 \\
\hline $\mathbf{4}$ & Bolt & Solid & 7830 & $2.75 \mathrm{e}+05$ & 0.26 \\
\hline $\mathbf{5}$ & Washer & Solid & 7830 & $2.75 \mathrm{e}+05$ & 0.26 \\
\hline $\mathbf{6}$ & Rubber & Solid & 1520 & 91.12 & 0.5 \\
\hline
\end{tabular}

In ABAQUS program as in many simulation programs, the values of the stress-strain data should be converted from engineering values into the true values because of the program contracts with the true values ratherthan engineering. These are completed by using the following equations (ABAQUS, 2017):

$$
\begin{gathered}
\sigma_{\text {true }}=\sigma_{\text {engineering }}\left(1+\varepsilon_{\text {engineering }}\right) \\
\varepsilon_{\text {true }}=\ln \left(1+\varepsilon_{\text {engineering }}\right) \\
\varepsilon_{\text {plastic }}=\ln \left(1+\varepsilon_{\text {engineering }}\right)-\frac{\sigma_{\text {true }}}{E_{\text {modulus }}}
\end{gathered}
$$

Table VIII illustrated the mechanical properties for the steel components that are used in the experimental test, these values are converted to the true values as to equations (ABAQUS, 2017).

TABLE VIII: $\quad$ True Value of Stress -Strain Proprieties

\begin{tabular}{ccc}
\hline \hline Parts & Yield Stress (MPa) & Plastic Strain \\
\hline Beam & 250.43 & 0 \\
\cline { 2 - 3 } & 400.7 & 0.30113 \\
\hline Column & 250.43 & 0 \\
& 400.7 & 0.28336 \\
\hline Plate & 312.54 & 0 \\
\hline Bolt & 422.73 & 0.28324 \\
\hline & 0 & 0.07401 \\
\hline
\end{tabular}




\section{Finite Element Mesh and Boundary Conditions}

The first step of the mesh procedure was dividing each individual imported part. The ABAQUS program need to define the complex geometry shapes, therefore, it is necessary for the user todivide the regions into simple geometry forms like to wedge or cube shapes. First-order hexahedral cubic elements were used for regularly shaped regions of structural meshing. Regarding of boundary conditions, five points in the bottom web and flange of the bottom column represent the 16 anchor bolts that fixed the specimen into the foundation of the laboratory test which constrain the fixed column in three $\mathrm{X}, \mathrm{Y}$ and $\mathrm{Z}$ directions and constrain the pinned column in two directions $\mathrm{Z}$ and $\mathrm{Y}$ only to prevent the model from moving during the test, and freely rotation about $\mathrm{X}$-axis. Figure (5)shows the constrain points for the FE models which are used in this research.

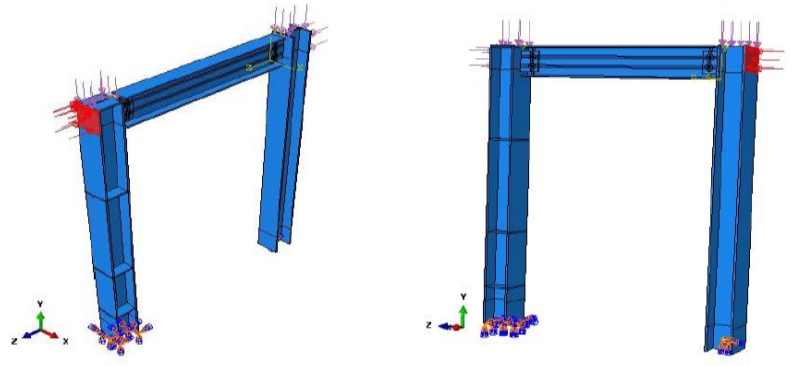

\section{Numerical results}

Figure 5: Load and Boundary conditions in the FE models.

Load-deflection P- $\Delta$ curves achieved from the ABAQUS program reveal that the FE element analysis provides acceptable and agreement solutions with the results which were found from the experimental test in this study. It is notables that the numerical and experimental behavior in the load-deflection curves was convergent. Except however, the theoretical curves were stiffer at the initial loading, but this behavior changed with increasing the loading until the failure occurred, where the final failure was lower than the laboratory test in this study. The ABAQUS solutions, however, were credible regarding the horizontal loading system as well as simulation of the models with or without rubberized steel frame connections. The numerical and experimental analysis drawing together in the load-deflection curves, for the horizontal cyclic loads along with the numerical solutions for the displacements on the Z- direction. All the data of ultimate loads and amplitude displacements for the experimental and numerical analysis are listed in Table IX. The difference between the experimental test and the numerical analysis for the ultimate resisting loads ranged between $4 \%$ and $16 \%$ and between $2 \%$ and $14 \%$ for the amplitude displacements. These ranges are considered within acceptable agreements. The results in the table are significant that using the rubber in the steel connection models increased the resisting loads for the specimens which were analyzed under horizontal loading effect FR2, FR3, and FR4by 25.5\%, 38.23, and 188.14\% compared with reference horizontal system FR1. Figures (6) illustrates the comparisons between numerical and experimental for the horizontal loading effect for the models FR1, FR2, FR3, and FR4.

TABLE IX:Comparison between Numerical and Experimental Results

\begin{tabular}{|c|c|c|c|c|c|c|c|}
\hline $\mathrm{NO}$ & Specimen & $\begin{array}{c}\boldsymbol{P}_{\boldsymbol{u}-\boldsymbol{E} \boldsymbol{X} \boldsymbol{P}} \\
(\mathrm{kN})\end{array}$ & $\begin{array}{c}\Delta_{\boldsymbol{u}-\boldsymbol{E X X P}} \\
(\mathrm{mm})\end{array}$ & $\begin{array}{c}P_{\boldsymbol{u}-\boldsymbol{F E} \boldsymbol{M}} \\
(\mathrm{kN})\end{array}$ & $\begin{array}{c}\Delta_{\boldsymbol{u}-\boldsymbol{F} \boldsymbol{E} \boldsymbol{M}} \\
(\mathrm{mm})\end{array}$ & $\frac{P_{u-F E M}}{P_{u-E X P}}$ & $\frac{\Delta_{u-F E M}}{\Delta_{u-E X P}}$ \\
\hline 1 & FR1 & 30 & 17.85 & 26.65 & 15.36 & 0.89 & 0.86 \\
\hline 2 & FR2 & 40 & 26.24 & 33.45 & 25.67 & 0.83 & 0.98 \\
\hline 3 & FR3 & 40 & 41.18 & 36.84 & 38.88 & 0.92 & 0.94 \\
\hline 4 & FR4 & 80 & 47.00 & 76.79 & 41.13 & 0.96 & 0.87 \\
\hline
\end{tabular}




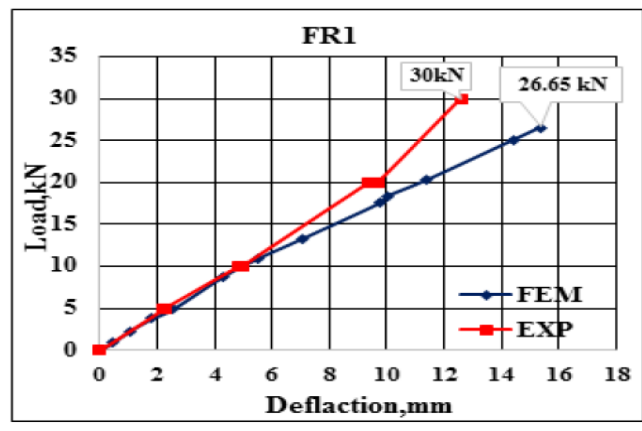

(A) FR1

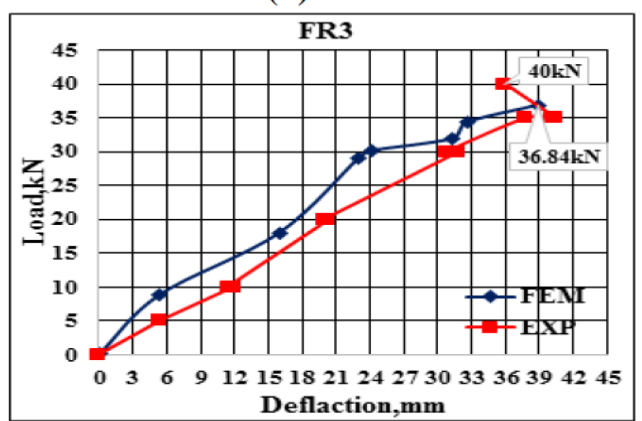

(C) FR3

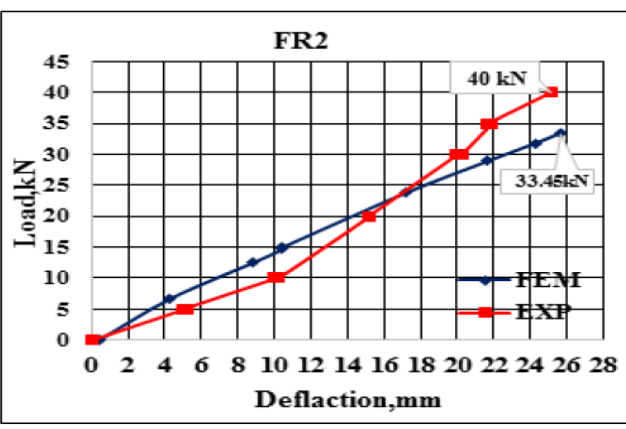

(B) FR2

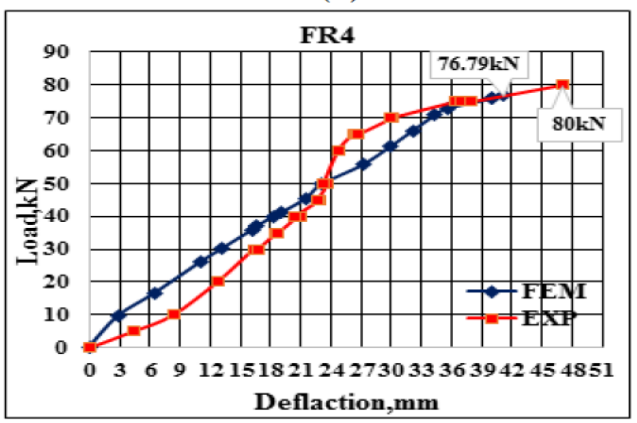

(D) FR4

Figure 6: Comparison of experimental and numerical $P-\Delta$ curves under cyclic loading.

Generally, the failure modes for the experimental specimens were fractured in the steel bolts at the peak loads and ended the test. The numerical solutions gave an acceptable mode failure and agree well with the laboratory test. Figure (7) illustrated the final deform shape for the shear tab connection conducted by the FE element and experimental test.The colors in Figure 6-A denote to the Von Mises stress distribution at the final of the simulation. Figure (8) illustrated the final mode failure for the numerical and experimental analysis, where a local buckling failure is observed in the bottom flanges of the fixed column, it is similar to the failure that occurred during the experimental test. The FE analysis appeared convergence with an experimental test in the mode failure for the bolts and washers as shown in Figure (9).

(A)

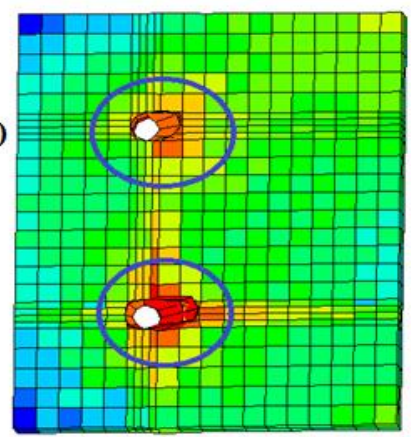

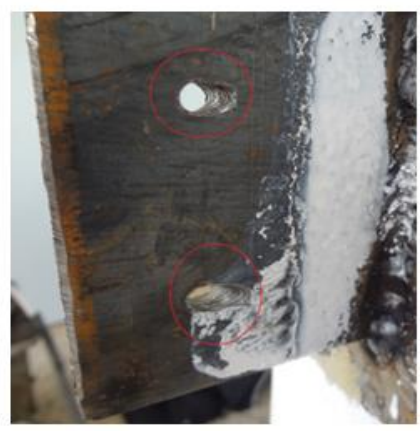

(B)

Figure 7: (A) FE deformation, (B) Experimental deformation 

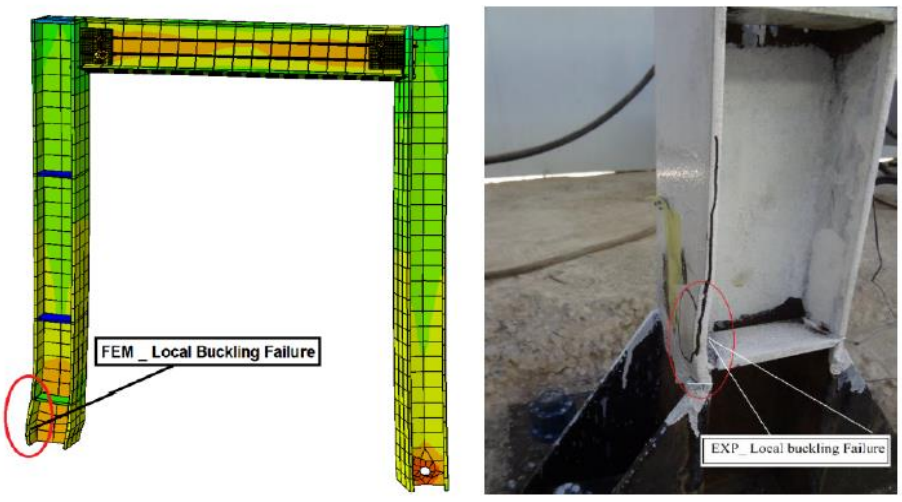

Figure 8: Mode of Failure Comparison between the Experimental Test and Numerical Analysis for the column FR1 specimen

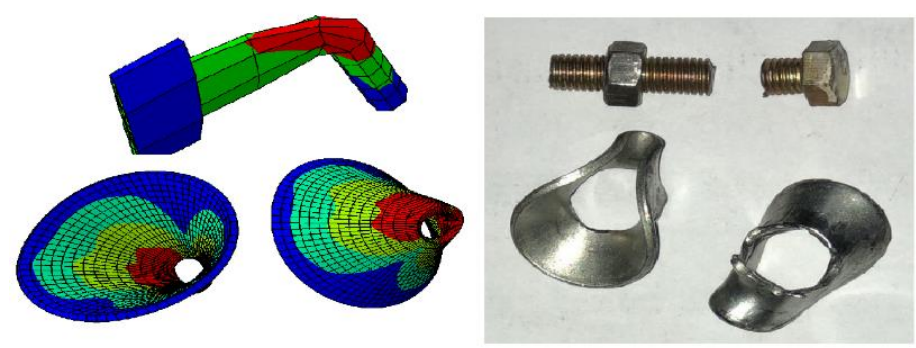

Figure 9: Mode of Failure Comparison between Experimental Test and Numerical Analysis for the bolts and washers FR1 specimen

\section{Conclusions}

The numerical and experimental analysis was performed to study the behavior of plane steel frames with rubberized connections under the seismic effect. The performance of steel frames concerning strength, ductility, and damping ratio. 3-D nonlinear finite element models were analyzed by using the general finite element program ABAQUS (2017) to establish the mechanical properties of these experimental specimens. The P- $\Delta$ curves and mode of failure used for comparisons of the numerical and experimental tests. From the results, it turns out using the rubber enhanced the behavior of the specimens, where the experimental test appeared that the strength of specimens increased by $33.33 \%$ to $167 \%$. So the FE methods performed the strength increased by $26 \%$ to $188 \%$. Using the rubber technical in the steel connections increased the damping effect by $2.46 \%$ to $28 \%$ of the reference frame without the rubber. From the results, the important notes should be mentioned that enhanced in the ductility index for the frames was significant by $55 \%, 145 \%$, and $182 \%$ which is a very important phenomenon for the building exposed to the earthquake effect, where for design the structure resist the earthquake that do not need to strengthen the structure, but needs to increase the ductility for these buildings. The process of manufacturing rubber from old tires is an economical process for recycling and the use of tires consumed. The practice of replacing traditional bolts with composites steel bolts/rubber is an easy application of steel structures constructed without resorting to the destruction or alteration of designs for the previous structures that did not design under seismic effect. Finally, the process of using the composites steel bolts/ rubber instead of the steel bolts ease of implementation for constructed steel structures without resorting to demolition or changing designs of facilities for which were not designed to resist the earthquake effect.

\section{References}

[1] W. Conference and E. Engineering, Cyclic Behavior of Traditional and Innovative, no. 2578, 2004.

[2] M. Asce and M. Sinclair, Structures Congress 2012 @ ASCE 2012 910, no. 2010, pp. 910-921, 2012. 
[3] J. M. Schroeder, Moment-Rotation Curves for Shear Tab Connections Using Finite Element Modeling and Experimental Data. 2012.

[4] M. Ggc and M. Biogas, Construction Manual, 2009.

[5] S. T. Methods, Standard Test Methods and Definitions for Mechanical Testing of Steel Products 1, 2017.

[6] A. S. Nuts et al., Standard Specification for Carbon Steel Bolts and Studs, 60000 PSI Tensile Strength , pp. $1-6,2010$.

[7] P. Materials and E. I. Materials, Standard Test Method for Tensile Properties of Plastics 1 D638-14, pp. 117, 2015.

[8] American Society for Testing and Materials, Compressive Properties of Rigid Plastics 1, Annu. B. ASTM Stand., vol. i, pp. 1-8, 2008.

[9] E. I. Materials, C. B. Manufacturing, D. Hardness, and C. Laboratories, Rubber Property-Durometer HardnesMaterials, E. I., Manufacturing, C. B., Hardness, D., \& Laboratories, C. (2017). Rubber PropertyDurometer Hardness 1Methods, S. T. (2008). Standard Test Methods for Rubber Property — Compression Set 1, i(Reapproved), 1-6., pp. 1-13, 2017.

[10] B. Taranath, Seismic Provisions for Structural Steel Buildings, ANSI/AISC 341-10, Struct. Anal. Des. Tall Build., pp. 355-410, 2012.

[11] ATC, Guidelines for cyclic seismic testing of components of steel structures, Atc-24, 1992.

[12] R. Sanaz and D. K. Armen, A stochastic ground motion model with separable temporal and spectral nonstationarities, Earthq. Eng. Struct. Dyn., 37 (2008) 1565-1584. https://doi.org/10.1002/eqe.831

[13] Fadhil H, Ibrahim A, Mahmood M. Effect of Corrugation Angle and Direction on the Performance of Corrugated Steel Plate Shear Walls. Civ. Eng. J., 4 (2018) 2667. 